\title{
Chapter 10 \\ Microstructural Crack Tip Plasticity Controlling Small Fatigue Crack Growth
}

\author{
Motomichi Koyama, Hiroshi Noguchi, and Kaneaki Tsuzaki
}

\subsection{Introduction: Small Crack Problem}

It has been generally recognized that resistance to small fatigue crack growth dominates the fatigue life and strength in numerous metallic structural components. "Small (short) cracks" have been classified as mechanically small cracks, microstructurally small cracks, physically small cracks, and chemically small cracks (Ritchie and Lankford 1986), the details of which are listed in Table 10.1. In this chapter, we note the growth of mechanically and microstructurally small cracks. We first indicate that the growth behaviors of mechanically and microstructurally small cracks are completely different from those of large cracks. Representative examples of the small crack growth characteristics are shown in Fig. 10.1. The small crack growth rate at a certain stress intensity factor range $(\Delta \mathrm{K})$ cannot be obtained through the extrapolation of a large crack growth rate curve in an identical material (Suresh and

\footnotetext{
${ }^{1}$ In this paper, short and small cracks, which have been used for two- and three-dimensional cracks, are not distinguished for discussion.
}

M. Koyama $\cdot$ K. Tsuzaki

Institute for Materials Research, Tohoku University, Katahira 2-1-1, Aoba-ku, Sendai 980-8577,

Miyagi, Japan

e-mail: koyama@imr.tohoku.ac.jp

Center for Elements Strategy Initiative for Structural Materials (ESISM), Kyoto University,

Yoshida-honmachi, Sakyo-ku, Kyoto 606-8501, Japan

H. Noguchi · K. Tsuzaki

Department of Mechanical Engineering, Kyushu University, Moto-oka 744, Nishi-ku, Fukuoka 819-0395, Japan

e-mail: nogu@mech.kyushu-u.ac.jp

K. Tsuzaki $(\bowtie)$

Research Center for Structural Materials, National Institute for Materials Science, Sengen 1-2-1,

Tsukuba 305-0047, Japan

e-mail: tsuzaki.kaneaki@nims.go.jp 
Table 10.1 Definitions of small fatigue cracks (Ritchie and Lankford 1986)

\begin{tabular}{|c|c|c|c|}
\hline Small crack & Characteristics & $\begin{array}{l}\text { Criterion for } \\
\text { determining a critical } \\
\text { crack length }\end{array}$ & References \\
\hline $\begin{array}{l}\text { Microstructurally } \\
\text { small }\end{array}$ & $\begin{array}{l}\text { Microstructure-dependent } \\
\text { Probabilistic crack growth }\end{array}$ & $\begin{array}{l}\text { Critical microstructure } \\
\text { size such, e.g. grain } \\
\text { size }\end{array}$ & $\begin{array}{l}\text { (Goto 1994; Omura } \\
\text { et al. 2017; Koyama } \\
\text { et al. 2017a; } \\
\text { Chowdhury and } \\
\text { Sehitoglu 2016) }\end{array}$ \\
\hline $\begin{array}{l}\text { Mechanically } \\
\text { small }\end{array}$ & $\Delta K$ is unavailable & Plastic zone size & $\begin{array}{l}\text { (Hironobu et al. } \\
\text { 1992; Li et al. 2017a) }\end{array}$ \\
\hline Physically small & $\begin{array}{l}\text { Simply small, showing } \\
\text { non-steady state crack } \\
\text { growth }\end{array}$ & $\begin{array}{l}\text { Engineering crack } \\
\text { length } \\
\text { e.g., }<0.5-1.0 \mathrm{~mm}\end{array}$ & $\begin{array}{l}\text { (Suresh and Ritchie } \\
\text { 1984; Fukumura } \\
\text { et al. 2017) }\end{array}$ \\
\hline Chemically small & $\begin{array}{l}\text { Chemical reaction on } \\
\text { crack surfaces significantly } \\
\text { acts }\end{array}$ & $\begin{array}{l}\text { Up to } 10 \mathrm{~mm} \text {, } \\
\text { depending on reaction } \\
\text { kinetics and frequency }\end{array}$ & (Gangloff 1985) \\
\hline
\end{tabular}

(a)

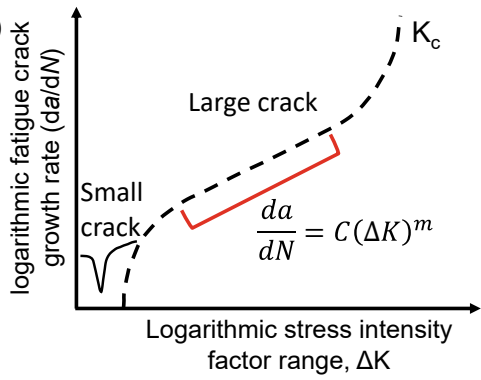

(b)

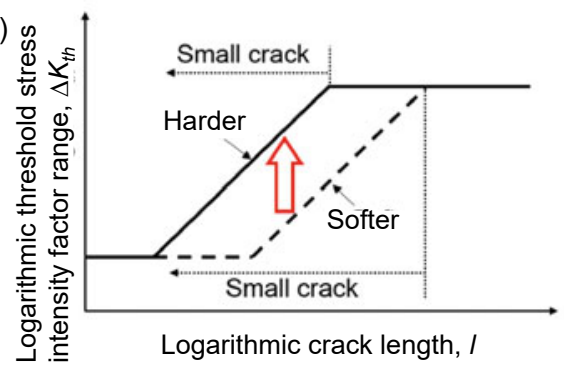

Fig. 10.1 Characteristics of small fatigue crack growth: (a) $\Delta K$ dependence of crack growth rate and (b) hardness sensitivity of $\Delta K_{\text {th }}$ with different initial crack lengths (Zhang et al. 2019). $K_{c}$ : fracture toughness. "Reproduced with permission from Metall. Mater. Trans. A, 50A, 1142 (2019). Copyright 2019, The Minerals, Metals \& Materials Society and ASM International"

Ritchie 1984) (Fig. 10.1(a)). Furthermore, the threshold stress intensity factor range $\left(\Delta \mathrm{K}_{\mathrm{th}}\right)$ for small crack growth is hardness-sensitive, unlike in the case of large cracks (Tanaka et al. 1981; Fukumura et al. 2015) (Fig. 10.1(b)). Therefore, we need specific mechanical and microstructural design strategies to improve the resistance to small fatigue crack growth, which differs from that for large crack growth resistance.

Small crack growth occurs through two routes: (A) dislocation-emission-induced crack tip deformation and (B) damage accumulation along a microstructural feature near a crack tip. Specifically, in case (A), when a crack tip opens, a dislocation emission occurs at the crack tip. Such a dislocation emission allows for a plastic crack opening, which advances the crack tip position (Fig. 10.2(a)). Even after a crack closes during an unloading and compression process, the crack tip position does not move backward. Hence, one cycle of crack opening and closing increases the 


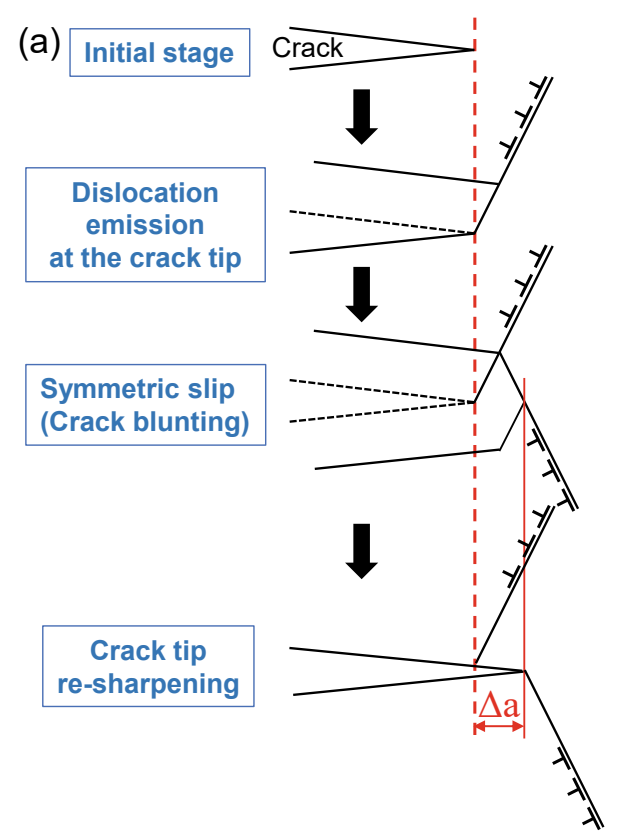

(b)

Initial stage

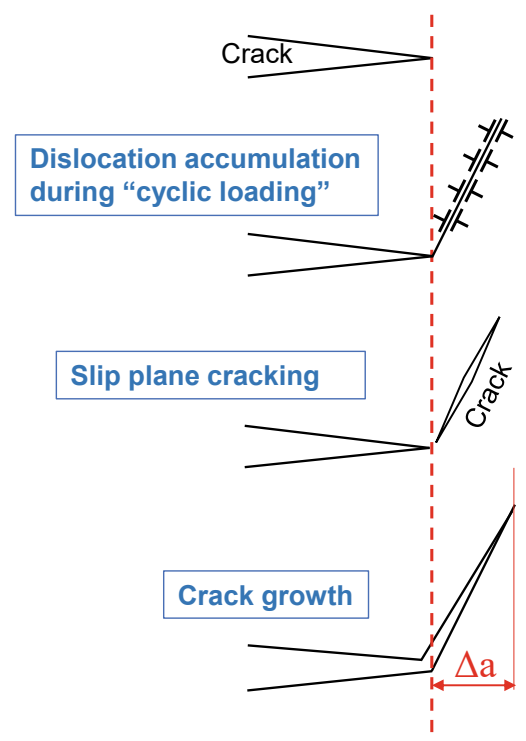

Fig. 10.2 Schematics of fatigue crack growth mechanisms driven by (a) dislocation emission at a crack tip and (b) damage accumulation near a crack tip

crack length, the degree of which is geometrically determined based on the number of emitted dislocations. In this regime, the lowest crack growth rate is an atomistic scale corresponding to one dislocation emission from the crack tip. In case (B), the role of the dislocations changes, namely, a local accumulation of dislocations causes microvoid or micro-crack formations near and/or at a crack tip through an increase in the local stress, the formation of vacancies, and the formation of a persistent slip band, which is referred to as damage accumulation and evolution. A damage-driven fatigue crack formation causes a discontinuous crack growth, which is strongly dependent on the microstructure of the crack tip (Fig. 10.2(b)). As understood from these basic mechanisms, the primary key to controlling the fatigue crack growth is crack tip plasticity. More specifically, the factors affecting the crack growth rate are divided into (1) resistance to plastic deformation, (2) resistance to damage/crack formation, (3) the crack tip deformation geometry, and (4) the crack closure effect. The first factor is directly associated with resistance to dislocation nucleation at a crack tip and to dislocation motion near a crack tip. The second factor is related to how the dislocation motion results in damage, such as vacancies, micro-voids, or micro-cracks. The third factor indicates the crystallographic relationship between the crack growth rate and crack tip/wake deformation. The fourth factor is a decrease in the actual stress or stress intensity factor at a crack tip, which is associated with a plastic zone evolution that realizes a lower crack tip stress than the elastic solution estimated based on the remote stress and crack shape and/or size. Considering the plasticity-controlled 


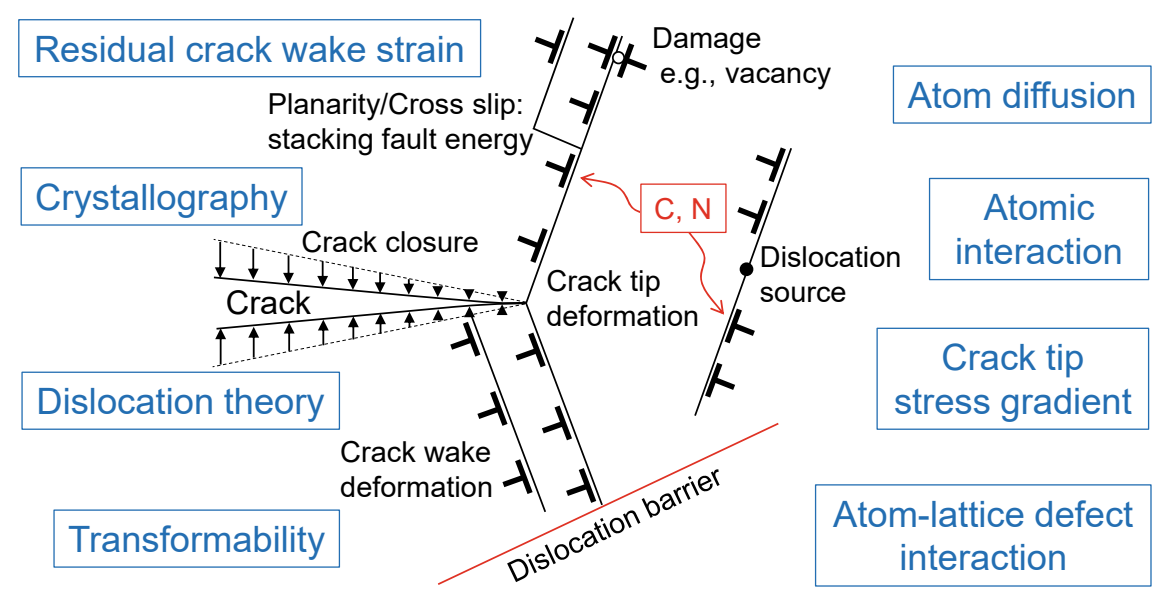

Fig. 10.3 Mechanical-metallurgical mechanism-based strategy for controlling small fatigue crack growth

factors, herein we introduce mechanical-metallurgical mechanism-based strategies for controlling small fatigue crack growth, as schematically shown in Fig. 10.3.

\subsection{Grain Refinement: Characteristic Distributions of Dislocation Barrier and Source}

First, we introduce the grain refinement effects on small crack growth, as well as a characteristic effect of ultrafine grains (UFG). As is well known, grain refinement increases the yield strength, which follows a Hall-Petch relationship (Tsuji et al. 2002). The enhancement of the yield strength and associated increase in hardness also increases the fatigue strength (Fig. 10.4(a)), which stems from the grain boundary acting as a dislocation barrier. Also note that the fatigue life of UFG steel at each stress amplitude is longer than that of coarse grained (CG) steel even after normalization by hardness (Fig. 10.4(b)), which implies an activation of extra factors. One possible factor is that grain boundaries can act as a dislocation source in ultrafine-grained materials owing to a lack of mobile dislocations in the grain interior. This effect alters the plastic strain gradient near the crack tip (Figs. 10.4(c, d)), which may affect the plasticity-induced crack closure (PICC) behavior. Moreover, the crack surface roughness, which also affects the crack growth resistance, is dependent on the grain size (Figs. 10.4(e, f)). In this section, we show the possible effects of a grain refinement on small fatigue crack growth in terms of the grain boundary roles as a dislocation source and barrier. $^{2}$

\footnotetext{
${ }^{2}$ In this paper, we do not show the effect of grain size on crack roughness, because of the limitation of pages. Please see the references (Suresh and Ritchie 1982) Suresh S, Ritchie RO. A geometric
} 
(a)

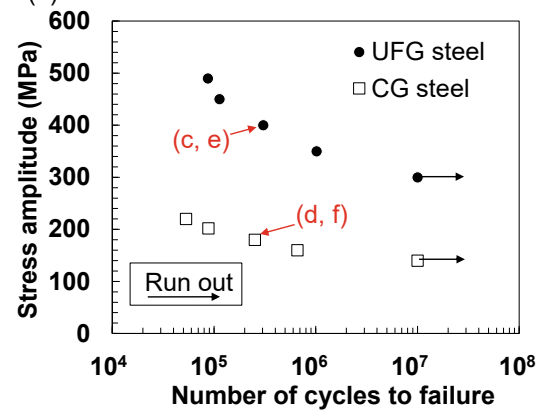

(b)

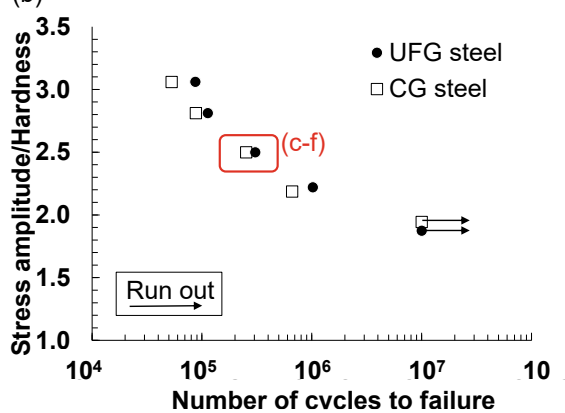

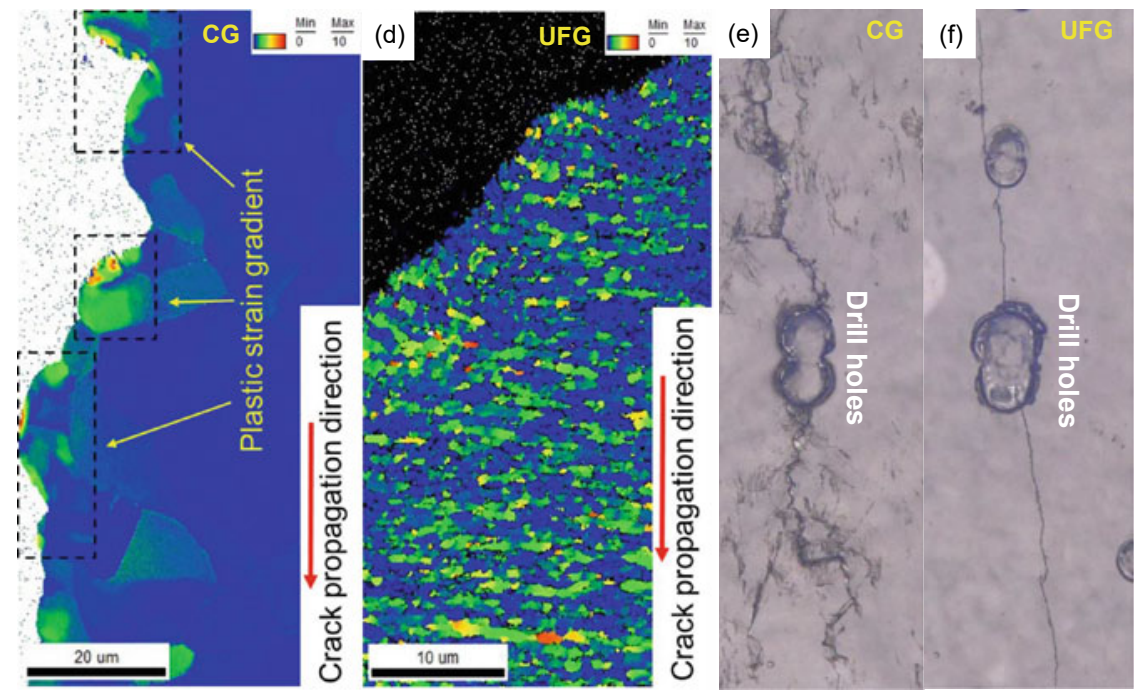

Fig. 10.4 Fatigue property and associated small fatigue crack growth in CG and UFG IF steels. The grain sizes of CG and UFG steels were $59 \mu \mathrm{m}$ and $590 \mathrm{~nm}$, respectively. (a) Stress amplitudenumber of cycles to failure (S-N) diagram, and (b) corresponding hardness-normalized $\mathrm{S}-\mathrm{N}$ curve. (c, d) Grain reference orientation deviation maps of CG and UFG steels. (e, f) Replica images showing a significant difference in crack roughness between CG and UFG steels (Lin et al. 2019). "Reproduced with permission from Int. J. Fatigue, 118, 117 (2019). Copyright 2018, Elsevier"

The crack tip plasticity interacts with the grain boundary, and its degree increases with a decrease in the distance between the crack tip and the grain boundary, which decelerates the crack growth. Hence, when the PICC effect is not considered, the

model for fatigue crack closure induced by fracture surface roughness. Metallurgical Transactions A. 1982;13:1627-31, (Niendorf et al. 2010) Niendorf T, Rubitschek F, Maier HJ, Canadinc D, Karaman I. On the fatigue crack growth-microstructure relationship in ultrafine-grained interstitialfree steel. Journal of Materials Science. 2010;45:4813-21, (Lin et al. 2019) Lin X, Koyama M, Gao S, Tsuji N, Tsuzaki K, Noguchi H. Resistance to mechanically small fatigue crack growth in ultrafine grained interstitial-free steel fabricated by accumulative roll-bonding. International Journal of Fatigue. 2019;118:117-25. 

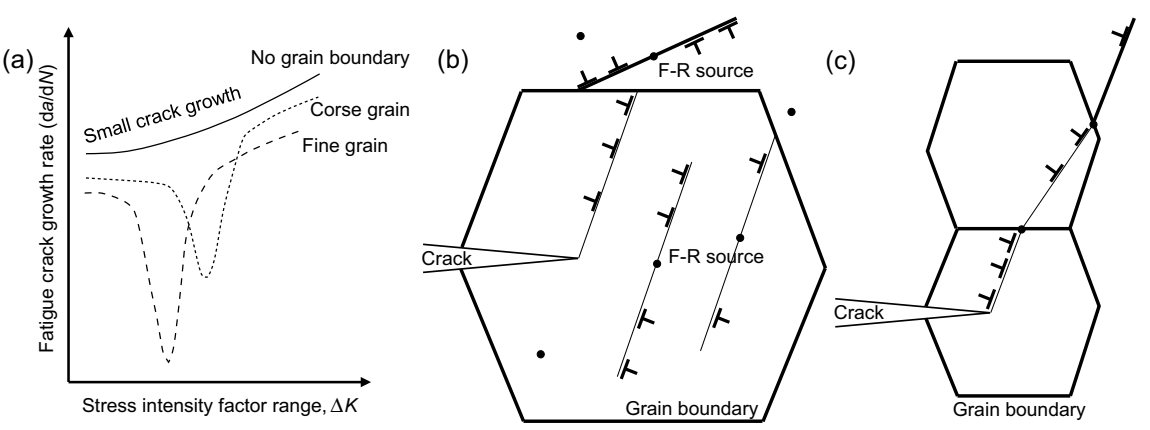

Fig. 10.5 Assumed grain size effect on small fatigue crack growth when the grain size is at the $\mu \mathrm{m}$ scale or larger (Lankford 1982). (a) Schematics for dislocation emission, motion, and multiplication in (b) CG and (c) UFG metals. The black dots indicate a Frank-Read (F-R) source or grain boundary acting as a dislocation source

rate of crack growth decreases until the crack grows to the first grain boundary, and then increases after the crack penetrates the boundary. As schematically shown in Fig. 10.5(a), the grain refinement enhances the grain boundary effect (sharply decreasing the crack growth rate), although the effect only occurs for a very small crack length or low stress intensity factor range. Furthermore, UFG metals have been recognized to show plasticity-induced softening and subsequent plastic deformation propagation. When the grain size is large (CG metal), plastic deformation around the crack tip occurs through dislocation emissions from the crack tip and dislocation multiplication from the Frank-Read sources. Compared to this deformation in CG metals, UFG metals can show a different dislocation behavior owing to a low density of mobile dislocations in the grain interior (Huang et al. 2006). Specifically, once the crack tip plasticity initiates in UFG metals, grains surrounding the crack tip become highly distorted plastically because plasticity-induced softening occurs through mobile dislocation emissions and multiplication. The grain distortion associated with the accumulation and pile-up of geometrically necessary dislocations causes dislocation emissions from the grain boundaries to the neighboring grain, which results in the propagation of a grain-scale deformation. A chain reaction of the plastic deformation in UFG metals may decrease the gradient of plastic strain near the crack tip. Because a plastic strain gradient is one of the origins of PICC, the propagation of a deformation across the grain boundaries may decrease the contribution of PICC in UFG metals (Lin et al. 2019). Consequently, in terms of crack tip plasticity, grain refinement has an ambivalent role ${ }^{2}$ in small crack growth because a grain boundary acting as dislocation barrier decelerates such growth, although when acting as a source it can accelerate the crack growth. 


\subsection{Plasticity-Induced Transformation: Thermodynamic-Based Design}

\subsubsection{Geometrical Effect on Crack Tip Deformation}

In terms of crack tip plasticity, a martensitic transformation involving transformation dislocations can alter the crack growth behavior. Figure 10.6 shows an example of a transformation effect. The Fe-30Mn-6Al alloy in the figure shows no martensitic transformation and only dislocation slips. In contrast, the $\mathrm{Fe}-30 \mathrm{Mn}-6 \mathrm{Si}$ and $\mathrm{Fe}-$ $30 \mathrm{Mn}-4 \mathrm{Si}-2 \mathrm{Al}$ alloys show a martensitic transformation from face-centered cubic (FCC: $\gamma$ ) to hexagonal close-packed (HCP: $\varepsilon$ ) structures. One difference between the $\mathrm{Fe}-30 \mathrm{Mn}-6 \mathrm{Si}$ and $\mathrm{Fe}-30 \mathrm{Mn}-4 \mathrm{Si}-2 \mathrm{Al}$ alloys is the plasticity of the HCP phase; namely, the HCP phase of the Fe-30Mn-6Si alloy shows brittle-like cracking, whereas that of the Fe-30Mn-4Si-2Al alloy is ductile (Nikulin et al. 2013). The crack growth rate of the $\mathrm{Fe}-30 \mathrm{Mn}-4 \mathrm{Si}-2 \mathrm{Al}$ alloy, which involves a $\gamma$ - $\varepsilon$ transformation, is significantly lower than that of the other alloys (Li et al. 2015; Ju et al. 2016), as shown in Fig. 10.6. More specifically, a "ductile" $\gamma-\varepsilon$ martensitic transformation decelerates the crack growth. Considering these facts, two underlying mechanisms of crack growth deceleration can be proposed. The first factor is reversible $\gamma \leftrightarrow \varepsilon$ transformation-induced plasticity (Sawaguchi et al. 2008, 2015), which can suppress the fatigue damage evolution associated with a vacancies and persistent slip bands near a crack tip ( $\mathrm{Ju}$ et al. 2016). The second factor is a geometrical effect of the transformation dislocation motion forming the HCP structure (Ju et al. 2017).

Herein, we introduce a model for explaining the second factor, as schematically shown in Fig. 10.7. When a crack tip opens through a slip of perfect dislocations, repeated symmetric dislocation emissions occur at the crack tip, which causes fatigue
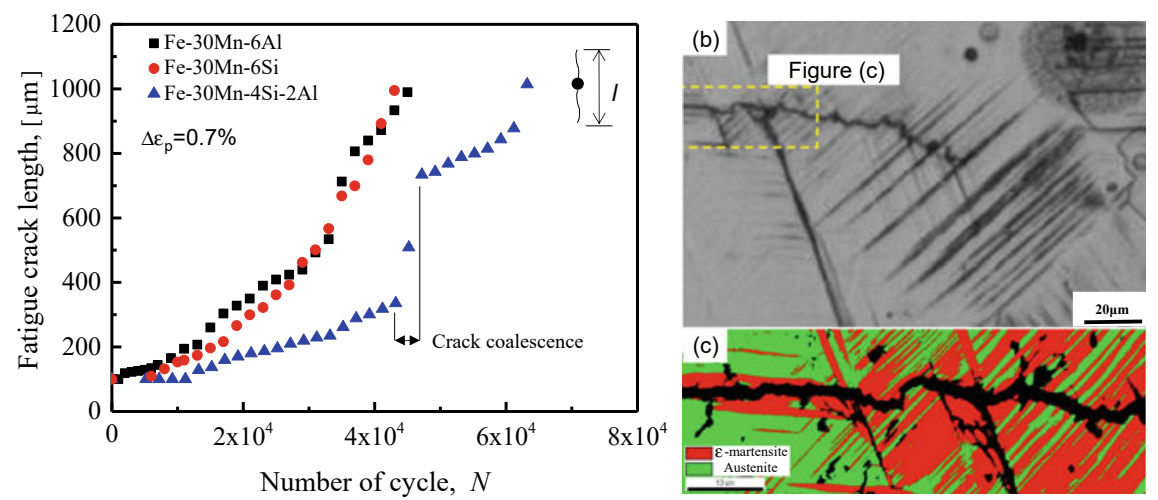

Fig. 10.6 Fatigue crack length plotted against number of cycles of three types of $\mathrm{Fe}-30 \mathrm{Mn}$-based alloys (a). Optical image of $\mathrm{Fe}-30 \mathrm{Mn}-4 \mathrm{Si}-2 \mathrm{Al}$ specimen surface fatigued until $4.3 \times 10^{4}$ cycles (b). (c) Phase map of region highlighted in (b) (Ju et al. 2016). "Reproduced with permission from Acta Mater., 112, 326 (2016). Copyright 2016, Elsevier" 


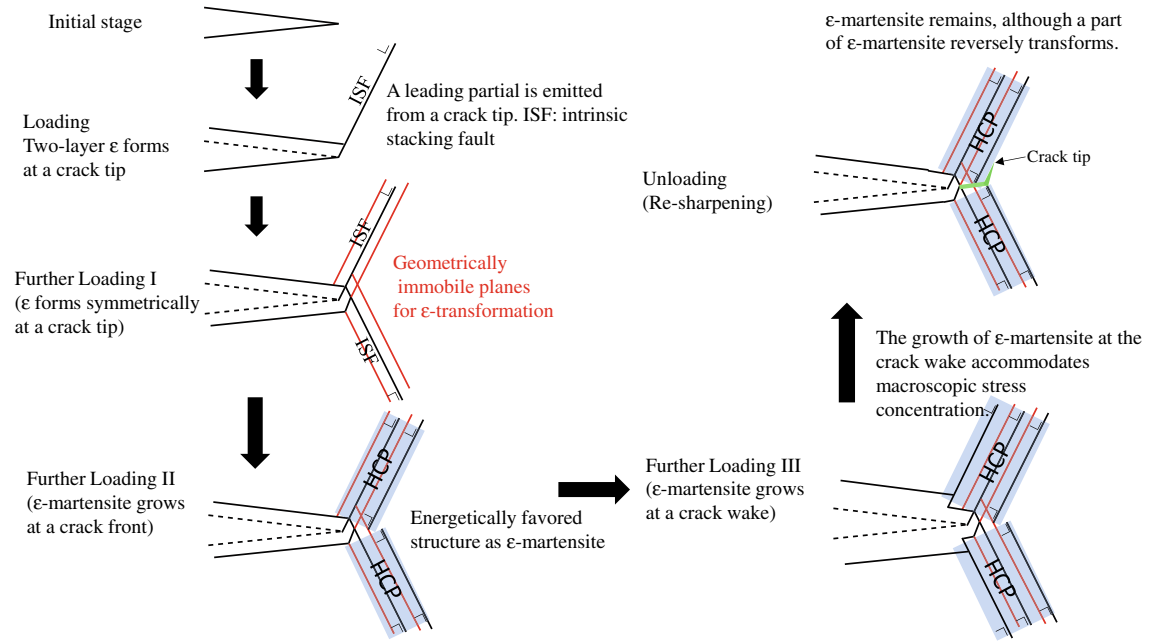

Fig. 10.7 Proposed model of a geometrical relationship between crack tip deformation and $\varepsilon$ martensitic transformation. The vertical direction corresponds to the loading direction (Ju et al. 2017). The red lines indicate the neighboring slip planes of the intrinsic stacking faults. "Reproduced with permission from Int. J. Fatigue, 103, 533 (2017). Copyright 2017, Elsevier”

crack growth for every cycle (Fig. 10.2(a)). In contrast, when the stacking fault energy is sufficiently low to induce a $\varepsilon$-martensitic transformation, the emission of a leading partial dislocation plays a role in the initial crack opening. To maintain the HCP structure, a second emission of a leading partial cannot occur on the identical slip plane. Furthermore, neighboring slip planes also cannot act as active planes for partial dislocation motions (if the partials move on the neighboring planes, the structure changes to an FCC twin.). Therefore, a second emission of leading partials must occur on the second-neighboring planes, which causes a crack wake deformation, and not a crack tip deformation. A crack wake deformation results in a crack opening, but does not contribute to Mode I crack growth. Because a portion of $\varepsilon$ martensite can reversely transform during an unloading and compression loading process, the effect of the $\gamma-\varepsilon$ martensitic transformation occurs repeatedly. This model suggests that a $\gamma-\varepsilon$ martensitic transformation at a crack tip alters the ratio between the crack tip opening displacement and the rate of crack growth, which decelerates the crack growth, particularly in strain-controlled fatigue tests. In other words, the use of a group motion of dislocations decelerates the crack growth rate, the effect of which can be enhanced when the deformation-induced phase involves long-range periodic structures. 


\subsubsection{Transformation-Induced Hardening and Lattice Expansion}

Figure 10.8(c) shows S-N diagrams of various types of austenitic steels with a small notch. All of the fatigue limits correspond to limits of fatigue crack non-propagation. As introduced later, $\mathrm{Fe}-23 \mathrm{Mn}-0.5 \mathrm{C}$ steel has been recognized to show a superior non-propagation limit compared to conventional austenitic steels, which can be used as a reference material for comparing the fatigue limit and strength. Note here that $\mathrm{Fe}-19 \mathrm{Cr}-8 \mathrm{Ni}-0.05 \mathrm{C}$ steel shows a martensitic transformation from FCC to a bodycentered cubic structure $\left(\gamma-\alpha^{\prime}\right.$ martensitic transformation). The fatigue limit and strength of $\mathrm{Fe}-19 \mathrm{Cr}-8 \mathrm{Ni}-0.05 \mathrm{C}$ steel are higher than those of the other types of steels, including $\mathrm{Fe}-23 \mathrm{Mn}-0.5 \mathrm{C}$ steel, even after normalization based on the hardness determined prior to the fatigue tests. As shown in Fig. 10.9, the region surrounding the crack in $\mathrm{Fe}-19 \mathrm{Cr}-8 \mathrm{Ni}-0.05 \mathrm{C}$ steel is fully covered with $\alpha^{\prime}$ martensite after the fatigue test even at the fatigue limit. In this context, the transformation-induced plasticity (TRIP) causes two phenomena that enhance the resistance to small fatigue

(a)

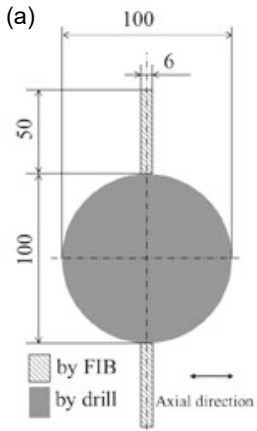

(b)

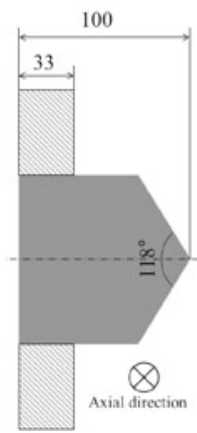

(c)

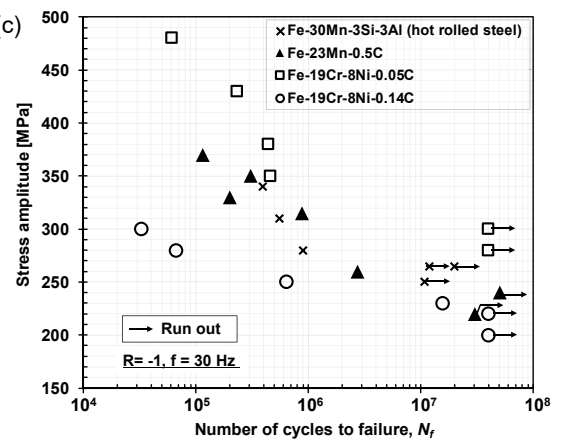

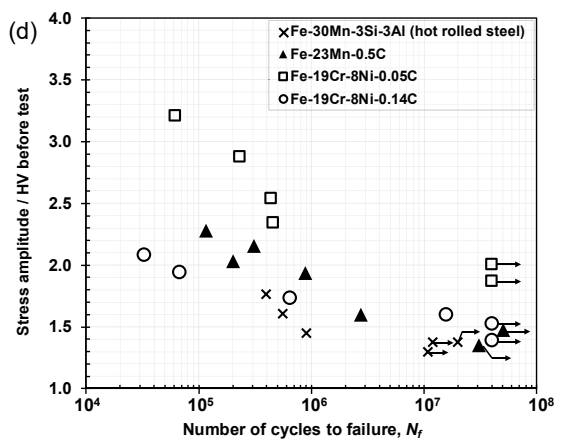

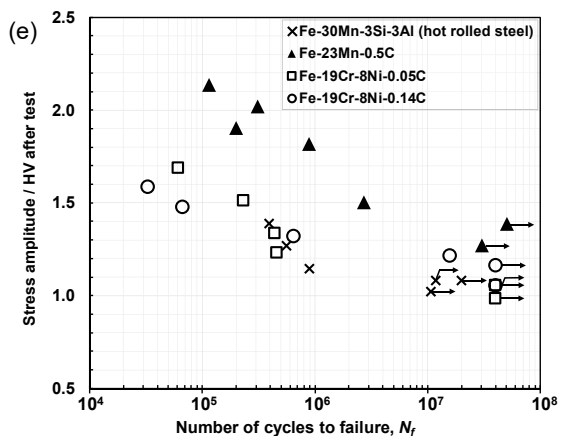

Fig. 10.8 Top and (b) side views of the micro-notch geometry (a). (c) S-N diagram of various types of austenitic steel. (d, e) S-N diagram normalized based on the Vickers hardness before and after the fatigue test at the fatigue limit (Nishikura et al. 2018). "Reproduced with permission from Int. J. Fatigue, 113, 359 (2018). Copyright 2018, Elsevier" 


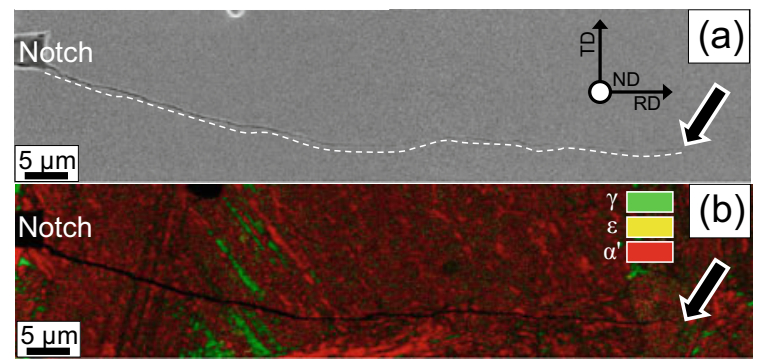

Fig. 10.9 SEM image (a) and (b) phase map of a location where a fatigue crack exists in $\mathrm{Fe}-19 \mathrm{Cr}-$ $8 \mathrm{Ni}-0.05 \mathrm{C}$ steel after fatigue testing for $4.0 \times 10^{7}$ cycles at $300 \mathrm{MPa}$ (fatigue limit) (Nishikura et al. 2018). The dashed line was drawn along the crack, and the arrows indicate a crack tip. " Reproduced with permission from Int. J. Fatigue, 113, 359 (2018). Copyright 2018, Elsevier"

crack growth: (1) work hardening (Ogawa et al. 2017, 2018) and (2) a transformationinduced crack closure (TICC) (Mei and Morris 1991; Mayer et al. 1995). The former is associated with a hard martensite phase and has been well recognized as having a TRIP effect during tensile tests, where the uniform elongation increases. The latter is associated with a lattice expansion arising from a close-packed structure (FCC) to a non-close-packed structure (BCC), which assists with the PICC. The TICC cannot act in the case of stress-controlled fatigue tests of $\mathrm{Fe}-19 \mathrm{Cr}-8 \mathrm{Ni}-0.05 \mathrm{C}$ steel because a $\gamma-\alpha^{\prime}$ martensitic transformation occurs not only near a crack but also in non-cracked regions; namely, a homogeneous transformation cannot cause a crack tip constraint under a stress control condition (only the specimen volume increases). Therefore, the first fact, i.e., work hardening, is the primary factor triggering the superior resistance to fatigue crack growth in $\mathrm{Fe}-19-\mathrm{Cr}-8 \mathrm{Ni}-0.05 \mathrm{C}$ steel. Correspondingly, when normalized based on the hardness evaluated after the fatigue tests at the fatigue limit, the fatigue limit of $\mathrm{Fe}-19 \mathrm{Cr}-8 \mathrm{Ni}-0.05 \mathrm{C}$ steel is lower than that of $\mathrm{Fe}-23 \mathrm{Mn}-0.5 \mathrm{C}$ steel (Figs. 10.8 (c) and (e)). By contrast, Fe-19Cr-8Ni-0.14C metastable austenitic steel, in which the extra carbon stabilizes the austenite (Ogawa et al. 2017), shows a lower fatigue limit than that of $\mathrm{Fe}-19 \mathrm{Cr}-8 \mathrm{Ni}-0.05 \mathrm{C}$ steel even when the fatigue limit is normalized based on the hardness prior to the fatigue test (Figs. 10.8 (c) and (d)), whereas the fatigue limit normalized by the hardness after the test in $\mathrm{Fe}-19 \mathrm{Cr}-$ 8Ni-0.14C steel is higher (Fig. 10.8(e)). These facts indicate that the higher fatigue limit normalized based on the hardness after the test in $\mathrm{Fe}-19 \mathrm{Cr}-8 \mathrm{Ni}-0.14 \mathrm{C}$ steel is attributed to the TICC associated with local transformation around the fatigue crack, and not to the effect of the work hardening. These results suggest that, to maximize the work hardening and TICC, the austenite stability must be optimized to induce a martensitic transformation locally around the crack while avoiding such an occurrence in a non-cracked region of the specimen. 


\subsection{Dislocation Planarity: Stress Shielding and Mode II Crack Growth}

Dislocation planarity is one of the most intrinsic characteristics controlling a longrange stress field and is enhanced by lowering the stacking fault energy and presence of short-range ordering, which increases the work hardening capability. Therefore, an enhancement of the dislocation planarity improves the tensile properties as long as no brittle cracking occurs; however, under fatigue, the dislocation planarity has both advantages and disadvantages regarding crack growth, which arise from the behaviors of the surface and interior of the specimen.

As a specific example, Fig. 10.10 shows a case of high-nitrogen austenitic steel with a chemical composition of $\mathrm{Fe}-25 \mathrm{Cr}-1 \mathrm{~N}$ that exhibits highly planar dislocation arrays owing to $\mathrm{Cr}-\mathrm{N}$ coupling. As shown in Figs. 10.10 (a) and (b), the fatigue limit of high-nitrogen steel is significantly higher than that of $\mathrm{Fe}-\mathrm{Cr}-\mathrm{Ni}$ austenitic stainless steel without interstitials, although surprisingly, the steel has more potential in terms of small crack growth resistance. In fact, even at a stress amplitude above the fatigue limit, crack growth of the main crack stops temporarily; however, a surface subcrack initiation at the main crack tip and a subsequent coalescence restart the growth of the main crack. Hence, the ease of subcrack initiation on the surface deteriorates
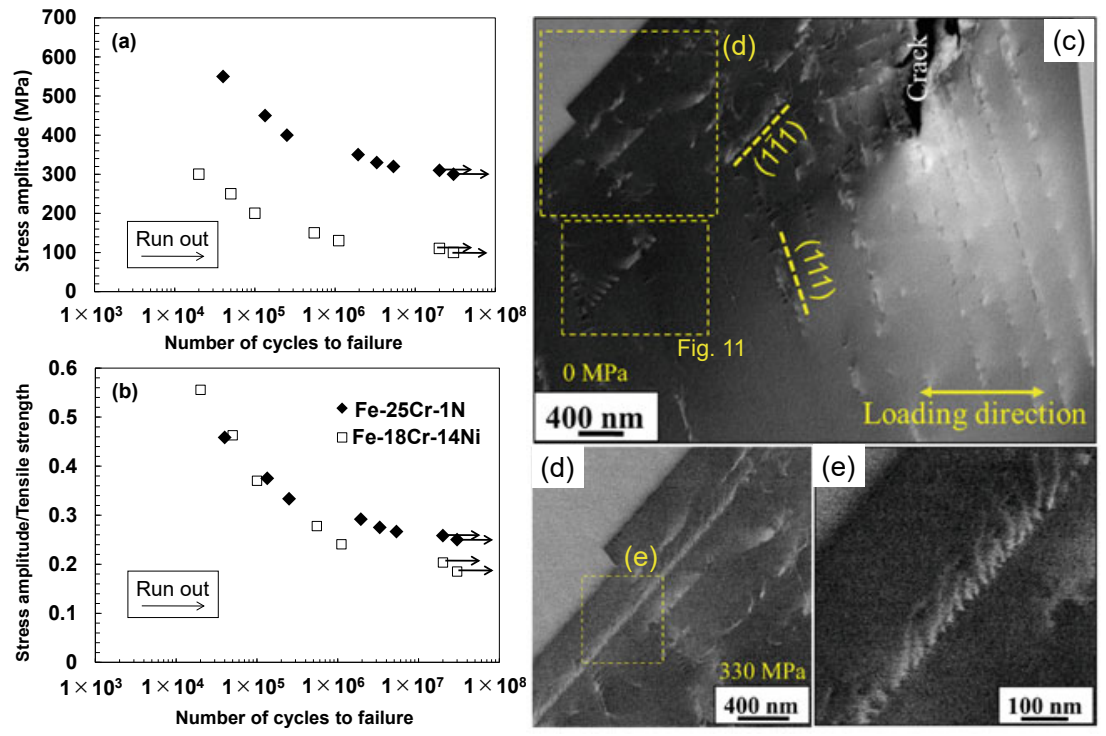

Fig. 10.10 S-N diagram of $\mathrm{Fe}-25 \mathrm{Cr}-1 \mathrm{~N}$ austenitic steel (a), and its normalized diagram based on the tensile strength (b) (Habib et al. 2017). ECC image showing crack tip microstructure after fatigue testing at $310 \mathrm{MPa}$ until $2 \times 10^{7}$ cycles (c). ECC image showing dislocation multiplication on a specific slip plane after further loading to $330 \mathrm{MPa}$ (d) and its magnification (e) (Habib et al. 2019a). "Reproduced with permissions from Int. J. Fatigue, 104, 158 (2017) Copyright 2017, Elsevier and Mater. Charact., 109,930 (2019) In press. Copyright 2019, Elsevier" 
the resistance to fatigue crack growth, which is attributed to a slip localization. In high-nitrogen steel, the dislocation motion is atomistically limited on the specific slip plane, as shown in Figs. 10.10 (d) and (e). Because a specimen surface is basically under a plane stress condition, a highly planar slip near the surface causes a localized out-of-plane plastic deformation through a dislocation emission to the surface during the tensile loading process. The localized out-of-plane deformation results in a surface relief that acts as a stress concentration site, bringing about another planar-slip-driven out-of-plane slip deformation with a different sign of dislocation during the unloading/compression process. The repetition of this process causes a dislocation dipole formation and persistent slip bands, which assists in fatigue crack initiation and associated crack growth. However, when a dislocation planar array exists in the interior of a specimen, the dislocation motion stops at a barrier, such as Lomer-Cottrell sessile dislocations, which results in a strong pile-up stress (Fig. 10.11(a)). Such pile-up stress prevents further dislocation motion on the identical slip plane during tensile loading, as shown in Figs. 10.11 (b)-(d), the effect of which has been recognized to suppress crack growth along the slip plane (Awatani et al. 1979). Subsequently, the pile-up stress enables reversible motion of the dislocations and associated stacking faults during unloading/compression process (c.f. Figure 10.12), which also enhances resistance to crack growth. Moreover, the dislocation pile-up stress can act as a shield for the tensile stress at the crack tip, which suppresses crack opening; in particular, Mode I crack growth is also prevented by the enhancement of dislocation planarity. Therefore, if the surface crack initiation can be suppressed, the enhancement of dislocation planarity has a significant potential to improve the resistance to a small crack growth in austenitic steel with a high-nitrogen content.

Similar to this context, an equiatomic Fe-Cr-Ni-Mn-Co high-entropy alloy, which is a recently noted material, also shows a similar behavior (Suzuki et al. 2018). High-entropy alloy has been reported to exhibit a low stacking fault energy $\left(30 \pm 5 \mathrm{~mJ} / \mathrm{m}^{2}\right.$ (Okamoto et al. 2016)) and a short-range ordering (Ding et al. 2018), thereby resulting in a highly planar slip in fatigued specimens. Correspondingly, once

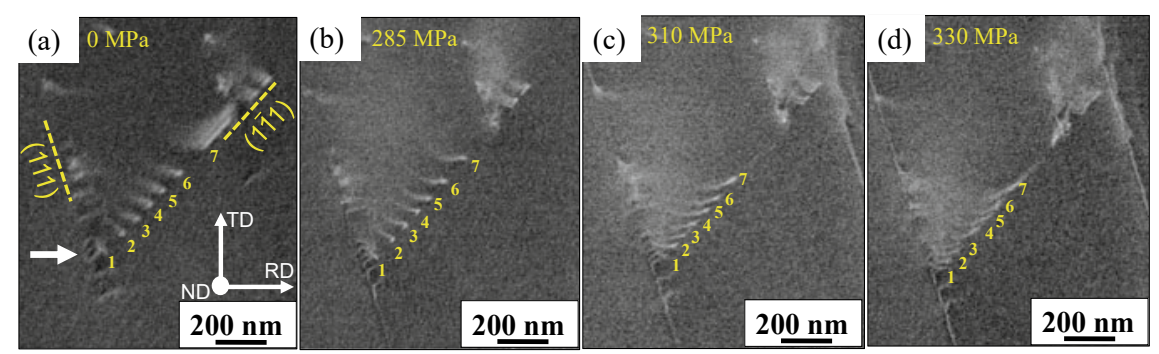

Fig. 10.11 ECC images during loading slightly far from the crack tip in the region outlined in Fig. 10.10(c) at (a) 0, (b) 285, (c) 310, and (d) $330 \mathrm{MPa}$. The white arrow in (a) indicates the location where multiple slips intersect each other (Habib et al. 2019a). "Reproduced with permission from Mater. Charact., 158, 109,930 (2019). Copyright 2019, Elsevier” 

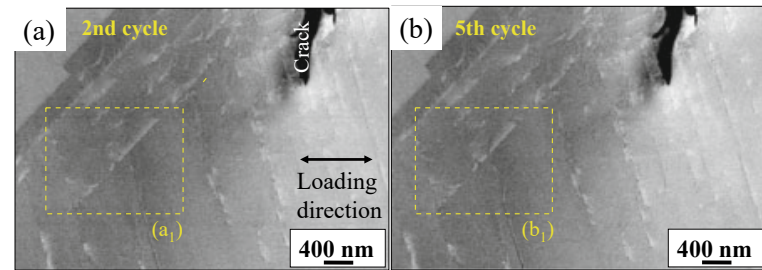

(c)
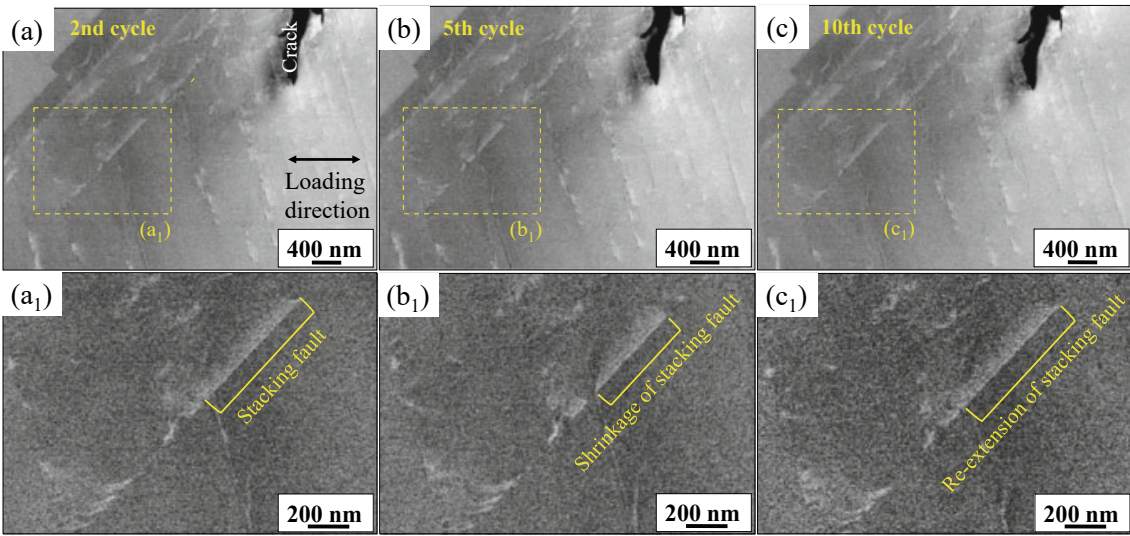

Fig. 10.12 ECC images during the cyclic loading after the 1-cycle in situ experiment of Figs. 10.10 and 10.11: (a) 2nd, (b) 5th, and (c) 10th cycles. $\left(a_{1}\right)$, ( $\left.b_{1}\right)$, and $\left(c_{1}\right)$ Magnified images of the section outlined by the yellow line in (a), (b), and (c), respectively (Habib et al. 2019a). "Reproduced with permission from Mater. Charact., 158, 109,930 (2019). Copyright 2019, Elsevier”

the small crack growth stops, it restarts through a crack coalescence (Suzuki et al. 2018), which is the same characteristic found in high-nitrogen steel. As mentioned, lowering the stacking fault energy is essential to improving the tensile properties, and the short-range ordering is expected to be used for next-generation high-strength alloys such as high-nitrogen steel and high-entropy alloys. Therefore, controlling the dislocation planarity and its associated surface subcrack initiation is a key to realizing a drastic improvement in the fatigue crack growth resistance in high-tensile strength alloys.

\subsection{Kinetic Effects of Solute Atoms on Crack Tip Plasticity}

\subsubsection{Strain-Age Hardening}

The occurrence of strain-age hardening at a crack tip has been recognized to improve the non-propagation limit of fatigue cracking. For instance, solute $\mathrm{Mg}$ in $\mathrm{Al}$ alloys (Shikama et al. 2012; Zeng et al. 2012; Takahashi et al. 2015) and solute carbon in steel (Li et al. 2016, 2017b, 2018; Kishida et al. 2018), both of which trigger strain aging, significantly improve the $\Delta \mathrm{K}_{\mathrm{th}}$ of small crack growth. Figure 10.13 shows an example of the carbon effect on $\Delta \mathrm{K}_{\mathrm{th}}$ in steel. The occurrence of dynamic strain aging can be confirmed in terms of the stress-strain response under tension. Interstitial free (IF) steel, which does not contain solute carbon, shows a smooth stress-strain curve, regardless of the strain rate (Fig. 10.13(a)). In contrast, Fe-0.017C steel, in which all carbon exists in a solute form, shows a serrated flow, particularly at low 

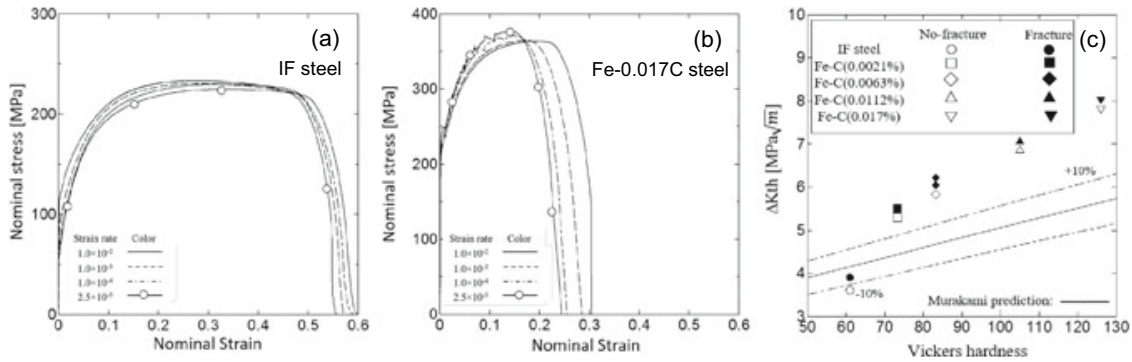

Fig. 10.13 Nominal stress-strain curves of (a) IF and (b) Fe-0.017C steel. (c) $\Delta K_{\text {th }}$ plotted against Vickers hardness ( $\mathrm{Li}$ et al. 2017b). The dashed lines in (c) indicate a 10\% error from the prediction using Murakami's equation. “ Reproduced with permission from Int. J. Fatigue, 98, 101 (2017). Copyright 2017, Elsevier."

strain rates (Fig. 10.13(b)). The occurrence of a serrated flow is evidence of the contribution of dynamic strain aging to the stress-strain response. The degree of a serrated flow increases with an increase in the solute carbon from 0.002 to 0.017 mass\% ( $\mathrm{Li}$ et al. 2017b). Correspondingly, $\Delta \mathrm{K}_{\mathrm{th}}$ increases with an increase in the solute carbon concentration, as shown in Fig. 10.13(c). To explain the details shown in Fig. 10.13(a), herein we introduce an empirical relationship between the hardness and $\Delta \mathrm{K}_{\text {th }}$ proposed by Murakami (Murakami 2019).

$$
\Delta K_{t h}=3.3 \times 10^{-3}(H V+120)(\sqrt{\text { area }})^{1 / 3},
$$

where $\mathrm{HV}$ is the Vickers hardness, $\sqrt{\text { area }}$ is the square root of the projected area of the initial defects, such as pre-cracks or inclusions. The effectiveness of the Murakami equation has already been demonstrated for the $\Delta \mathrm{K}_{\text {th }}$ predictions of carbon steel with different initial notch geometries, and the prediction error was determined to be less than 10\% ( $\mathrm{Li}$ et al. 2016; Murakami 2019). The solid and dotted lines in Fig. 10.13(c) indicate the predicted values and their $10 \%$ errors, respectively. The measured $\Delta \mathrm{K}_{\text {th }}$ of IF steel is within the $\pm 10 \%$ error band shown in Fig. 10.13(c), whereas the four types of $\mathrm{Fe}-\mathrm{C}$ steel with different carbon contents show a higher $\Delta \mathrm{K}_{\mathrm{th}}$ than the predicted value of $+10 \%$. Furthermore, the difference between the predicted and measured $\Delta \mathrm{K}_{\mathrm{th}}$ values increases with an increase in the carbon content. These facts indicate that the dynamic strain aging arising from solute carbon occurs particularly in the plastic zone, which increases the crack tip hardness during fatigue tests. As a result, the presence of solute carbon overcomes the conventionally known hardness $-\Delta \mathrm{K}_{\mathrm{th}}$ relation. 


\subsubsection{Effects of $i-s$ Interaction}

A problematic issue in utilizing the effect of strain-age hardening is a limitation of the solute diffusivity at room temperature. For example, normal austenitic steel does not show dynamic strain-age hardening even if the steel contains carbon or nitrogen in the solute because their diffusivity is insufficient for $\mu \mathrm{m}$-scale atom motions. This problem can be solved using attractive interactions of interstitialsubstitutional atoms (i-s). As introduced in Sect. 10.4, $\mathrm{Cr}-\mathrm{N}$ interaction enhances the dislocation planarity, whereas another type of i-s interaction, i.e., $\mathrm{Mn}-\mathrm{C}$, assists strain-age hardening in austenitic steel at room temperature (Koyama et al. 2018a). Figure 10.14(a) shows an S-N diagram of Fe-23Mn-0.5C and Fe-30Mn-3Si-3Al austenitic steels. Both types of steels show deformation twinning and a dislocation glide, although only $\mathrm{Fe}-23 \mathrm{Mn}-0.5 \mathrm{C}$ steel demonstrates dynamic strain-age hardening even at room temperature. $\mathrm{Fe}-30 \mathrm{Mn}-3 \mathrm{Si}-3 \mathrm{Al}$ does not show non-propagating fatigue cracks, whereas Fe-23Mn-0.5C clearly does, as indicated in Figs. 10.14(bd); namely, the $\mathrm{Mn}-\mathrm{C}$ coupling improves the limit of fatigue crack non-propagation

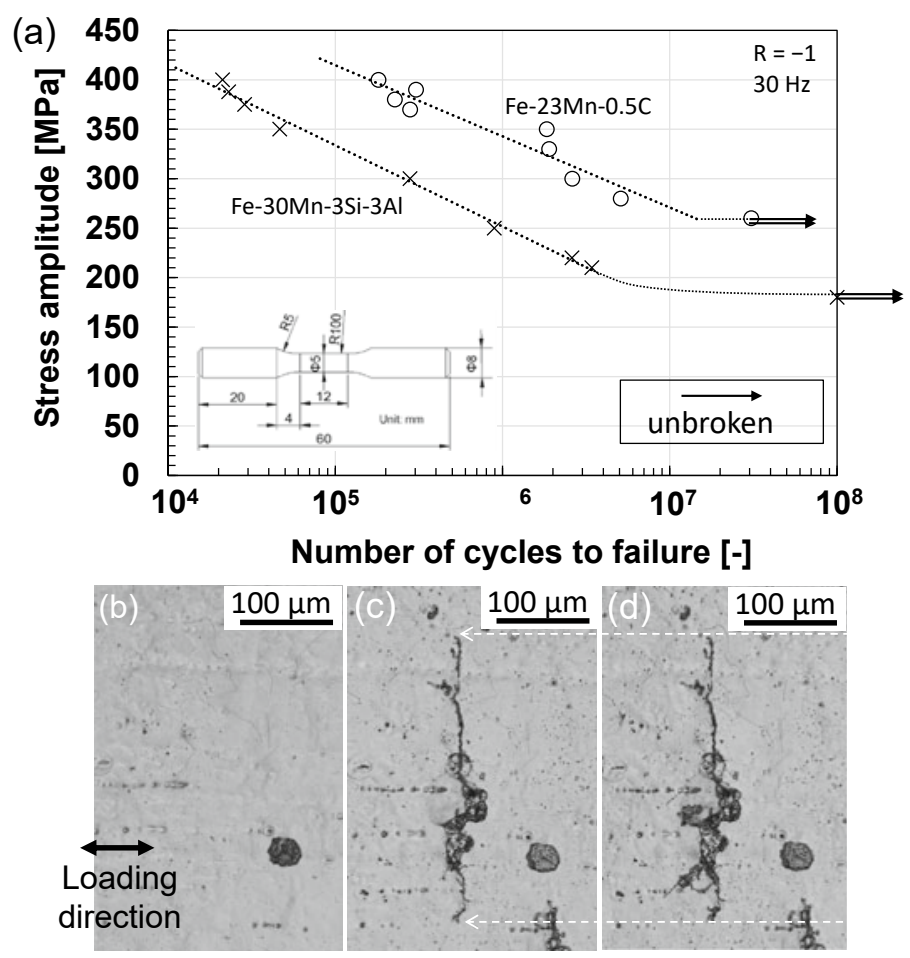

Fig. 10.14 Stress amplitude-fatigue life diagrams of smooth specimens (a). Replica images showing the non-propagation of a small crack in Fe-23Mn-0.5C at (b) 0 , (c) $1 \times 10^{7}$, and (d) $3 \times$ $10^{7}$ cycles (Koyama et al. 2017b). “ Reproduced with permission from Int. J. Fatigue, 94, 1 (2017) Copyright 2016, Elsevier." 

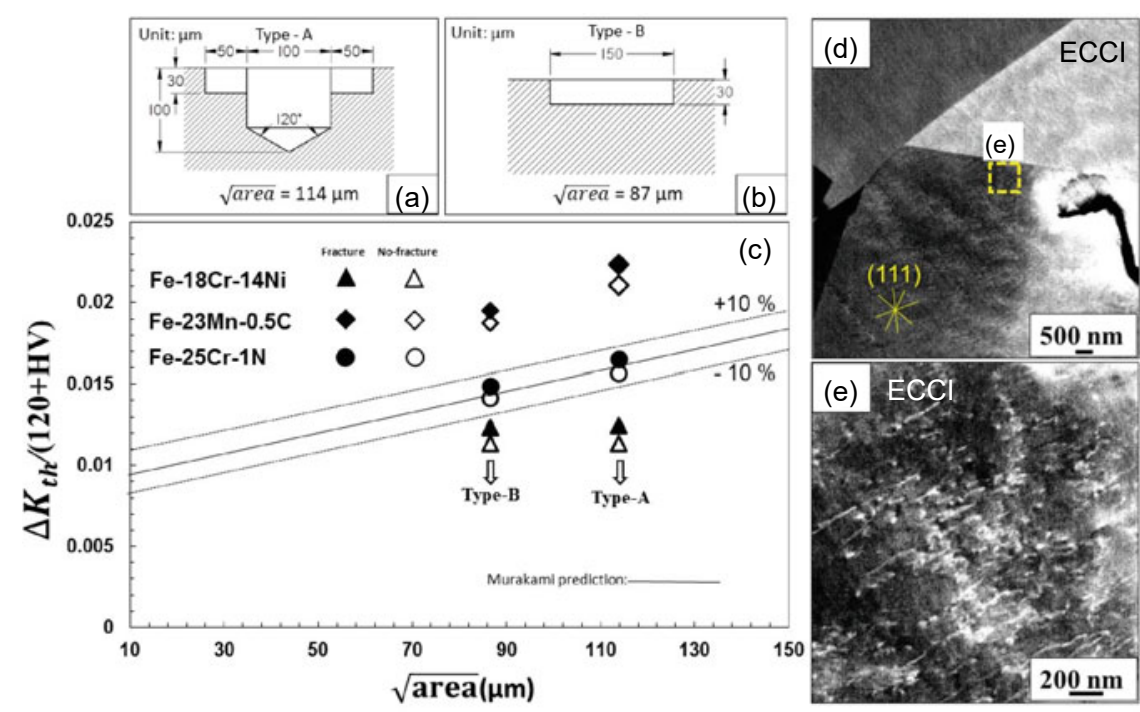

Fig. 10.15 Micro-notch geometries $(\mathbf{a}, \mathbf{b})$ and $(\mathbf{c})$ associated $\Delta K_{\text {th }}$ data normalized using 120 $+\mathrm{HV}$. (d) Non-propagating crack tip microstructure and (e) its magnification in $\mathrm{Fe}-23 \mathrm{Mn}-0.5 \mathrm{C}$ (Habib et al. 2019b). "Reproduced with permission from Metall. Mater. Trans. A, 50A, 426 (2019). Copyright 2018, The Minerals, Metals \& Materials Society and ASM International”

through a triggering of the dynamic strain-age hardening. Evaluating the $\Delta \mathrm{K}_{\mathrm{th}}$ of Fe$23 \mathrm{Mn}-0.5 \mathrm{C}$ steel, the non-propagation limit of a fatigue crack is higher than that of high-nitrogen austenitic steel. According to the ECCI characterization (Figs. 10.15(d, e)), a high dislocation density was confirmed at the tip of the non-propagating fatigue crack. The high dislocation density increases the crack tip hardness, which thereby improves the non-propagation limit of the fatigue crack. Hence, the use of i-s attractive interactions for strain-age hardening can be applied as a new alloy design strategy for the development of materials with a high resistance to high-cycle fatigue.

\subsection{Effect of Microstructural Hardness Heterogeneity: Discontinuous Crack Tip Plasticity}

The final example of a mechanical-metallurgical mechanism-based strategy is the use of a microstructural hardness heterogeneity. In a general sense, the introduction of soft portions is speculated to decrease the resistance to fatigue crack propagation; however, in a controlled case, the soft portion can increase the resistance to fatigue crack propagation owing to an enhancement of PICC ( $\mathrm{Li}$ et al. 2017a), an example of which is shown in Fig. 10.16. Figure 10.16(a) shows an RD-IPF map of hotrolled $\mathrm{Fe}-30 \mathrm{Mn}-3 \mathrm{Si}-3 \mathrm{Al}$ steel. Because of the recrystallization during hot-rolling, the grain size distribution appears heterogeneously. Moreover, the degree of plastic 

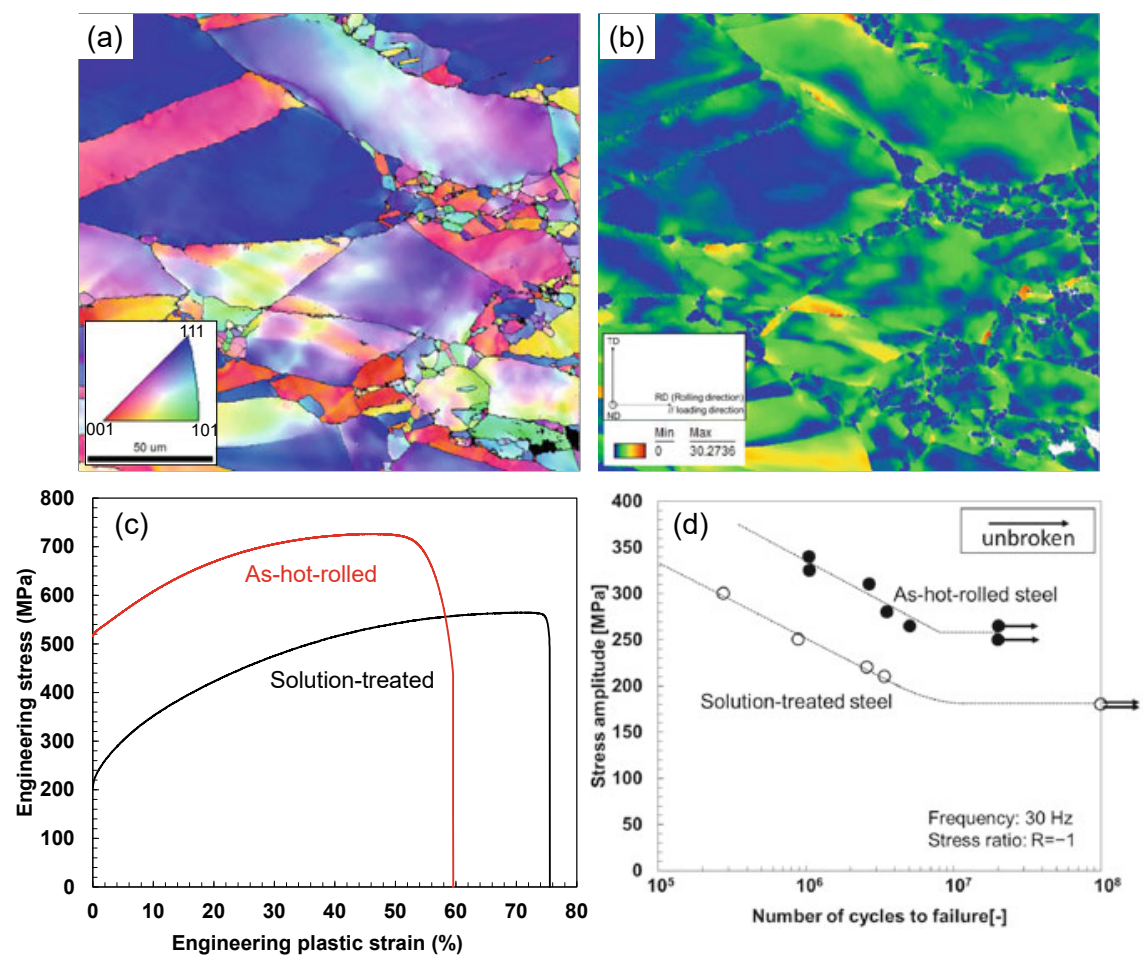

Fig. 10.16 RD-IPF (a) and GROD maps of as-hot-rolled Fe-30Mn-3Si-3Al steel (b). The hotrolling temperature was $1,273 \mathrm{~K}$. Engineering stress-strain (c) and stress amplitude-number of cycles to failure diagrams of the as-hot-rolled and solution-treated $\mathrm{Fe}-30 \mathrm{Mn}-3 \mathrm{Si}-3 \mathrm{Al}$ steel (d) (Koyama et al. 2018b). " Reproduced with permission from Int. J. Fatigue, 108, 18 (2018). Copyright 2017, Elsevier”

deformation is also heterogeneous (Fig. 10.16(b)). The partially fine grain and high dislocation density increase the yield and tensile strength, as shown in Fig. 10.16(c). The increase in tensile strength increases the fatigue limit (Fig. 10.16(d); however, the fatigue limits normalized by the respective tensile strength of the as-hot-rolled and solution-treated steel were 0.36 and 0.32 , respectively. Furthermore, the as-hot-rolled steel showed a non-propagating fatigue crack, whereas the solution-treated steel did not. An image of the non-propagating fatigue crack is shown in Fig. 10.17(a), and the crack is presented in the grain interior (Fig. 10.17(b). For further characterization of the crack, the specimen surface was slightly polished mechanically, as shown in Figs. 10.17 (c) and (d), and the identical region surrounding the crack tip was analyzed using EBSD (Figs. 10.17(e, f)). The crack tip was observed in the grain interior, as indicated in Fig. 10.17(d), and the crack propagated from a highly distorted region to a less distorted region, shown in Fig. 10.17(f). In other words, the crack propagated from the soft to hard regions, and stopped within the grain interior. According to a mechanical simulation using a Dugdale model, the plasticity mismatch at the interface 


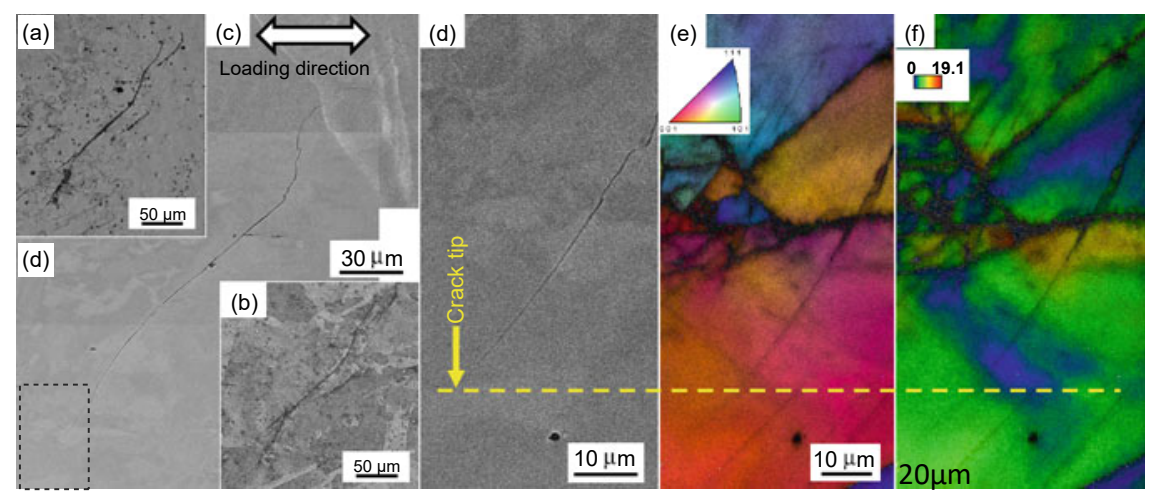

Fig. 10.17 A replica image (a) and corresponding optical micrograph of a chemically etched surface (b), which show a non-propagating crack in the as-hot-rolled $\mathrm{Fe}-30 \mathrm{Mn}-3 \mathrm{Si}-3 \mathrm{Al}$ steel. Overview of the fatigue crack after slight mechanical polishing (c). A magnified SEM image (d), and corresponding (e) RD-IPF and (f) GROD maps (Koyama et al. 2018b). " Reproduced with permission from Int. J. Fatigue, 108, 18 (2018). Copyright 2017, Elsevier"

of the soft and hard regions can enhance the effect of the PICC (Li et al. 2017a), which assists in the non-propagation of fatigue cracking. Therefore, even if the hardness or tensile strength is macroscopically identical, control of the microstructural hardness heterogeneity can improve resistance to fatigue crack growth.

\subsection{Summary}

In this chapter, we introduced mechanical-metallurgical mechanism-based strategies for improving the crack growth resistance in terms of the crack tip plasticity. Figure 10.18 schematically summarizes the factors that can enhance the resistance to small crack growth. Although respective factors were separately introduced, such factors interact with each other. For instance, the factors hardening the crack tip region definitely affect the behavior of a crack wake deformation. Therefore, thus far, a prediction of the small crack growth has been recognized to be a difficult issue. However, the coupling of multiple mechanisms can realize unexpected fatigue resistance through synergetic effects. In fact, we succeeded in presenting an outstanding fatigue resistance associated with the activation of multimechanisms in steel (Koyama et al. 2017c). We believe that there is a large frontier for fatigue-resistant material development on the design of a mechanical-metallurgical mechanism-based microstructure.

In addition, uncertain problems remain regarding small crack growth. Mode II type crack growth associated with damage (lattice defect) accumulation is one remaining unknown, but has frequently been observed in various types of metal including steel and titanium alloy (Habib et al. 2017; Maenosono et al. 2018, 2019; Mizumachi 


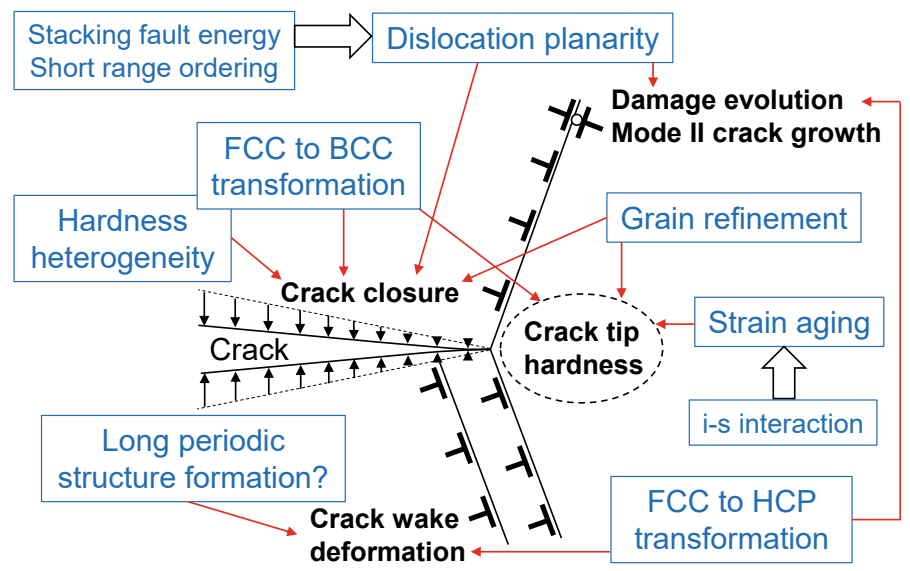

Fig. 10.18 Causes of the presented factors being affected by the fatigue crack growth

et al. 2019). The ease of Mode II crack growth affects the crack roughness (crack growth path), and discontinuous crack growth, and highly disturbs the mechanical laws of fatigue crack growth. The kinetic effects of solute atoms also still contain numerous uncertainties, which affect the temperature and frequency dependence of fatigue resistance. In fact, the importance of such kinetic effects has recently increased owing to the occurrence of hydrogen-accelerated fatigue crack growth in metal used for a hydrogen-related infrastructure (Murakami and Matsuoka 2010; Onishi et al. 2016). The problems of Mode II crack growth and kinetic effects of the solutes are clearly a mechanical-metallurgical issue, which is expected to be solved through the cooperation of mechanical engineers and metallurgists.

Acknowledgements This work was supported by Elements Strategy Initiative for Structural Materials (ESISM: JPMXP0112101000) of Ministry of Education, Culture, Sports, Science and Technology (MEXT) Japan, and JSPS KAKENHI (JP16H06365; JP20H02457).

\section{References}

Awatani J, Katagiri K, Koyanagi K (1979) A study on the effect of stacking fault energy on fatigue crack propagation as deduced from dislocation patterns. Metall Trans A 10:503-507

Chowdhury P, Sehitoglu H (2016) Mechanisms of fatigue crack growth-A critical digest of theoretical developments. Fatigue Fract Eng Mater Struct 39:652-674

Ding J, Yu Q, Asta M, Ritchie RO (2018) Tunable stacking fault energies by tailoring local chemical order in CrCoNi medium-entropy alloys. Proc Natl Acad Sci USA 115:8919-8924

Fukumura N, Suzuki T, Hamada S, Tsuzaki K, Noguchi H (2015) Mechanical examination of crack length dependency and material dependency on threshold stress intensity factor range with Dugdale model. Eng Fract Mech 135:168-186 
Fukumura N, Li B, Koyama M, Suzuki T, Hamada S, Tsuzaki K et al (2017) Material property controlling non-propagating fatigue crack length of mechanically and physically short-crack based on Dugdale-model analysis. Theor Appl Fract Mech 90:193-202

Gangloff RP (1985) Crack size effects on the chemical driving force for aqueous corrosion fatigue. Metall Trans A 16:953

Goto M (1994) Statistical investigation of the behaviour of small cracks and fatigue life in carbon steels with different ferrite grain sizes. Fatigue Fract Eng Mater Struct 17:635-649

Habib K, Koyama M, Tsuchiyama T, Noguchi H (2017) Fatigue crack non-propagation assisted by nitrogen-enhanced dislocation planarity in austenitic stainless steels. Int J Fatigue 104:158-170

Habib K, Koyama M, Tsuchiyama T, Noguchi H (2019b) ECCI characterization of dislocation structures at a non-propagating fatigue crack tip: Toward understanding the effects of $\mathrm{Mn}-\mathrm{C}$ and $\mathrm{Cr}-\mathrm{N}$ couples on crack growth resistance. Metall Mater Trans A 50:426-435

Habib K, Koyama M, Tsuchiyama T, Noguchi H (2019) Dislocation motion at a fatigue crack tip in a high-nitrogen steel clarified through in situ electron channeling contrast imaging. Mater Charact 158:109930

Hironobu N, Masahiro G, Norio K (1992) A small-crack growth law and its related phenomena. Eng Fract Mech 41:499-513

Huang X, Hansen N, Tsuji N (2006) Hardening by annealing and softening by deformation in nanostructured metals. Science 312:249-251

Ju Y-B, Koyama M, Sawaguchi T, Tsuzaki K, Noguchi H (2016) In situ microscopic observations of low-cycle fatigue-crack propagation in high-Mn austenitic alloys with deformation-induced $\varepsilon$-martensitic transformation. Acta Mater 112:326-336

Ju Y-B, Koyama M, Sawaguchi T, Tsuzaki K, Noguchi H (2017) Effects of $\varepsilon$-martensitic transformation on crack tip deformation, plastic damage accumulation, and slip plane cracking associated with low-cycle fatigue crack growth. Int J Fatigue 103:533-545

Kishida K, Koyama M, Yoshimura N, Sakurada E, Yokoi T, Ushioda K et al (2018) Effect of Si on temperature dependence of non-propagation limit of small fatigue crack in a Fe-C alloy. Procedia Struct Integr 13:1032-1036

Koyama M, Li H, Hamano Y, Sawaguchi T, Tsuzaki K, Noguchi H (2017a) Mechanical-probabilistic evaluation of size effect of fatigue life using data obtained from single smooth specimen: An example using Fe-30Mn-4Si-2Al seismic damper alloy. Eng Fail Anal 72:34-47

Koyama M, Yamamura Y, Che R, Sawaguchi T, Tsuzaki K, Noguchi H (2017b) Comparative study on small fatigue crack propagation between $\mathrm{Fe}-30 \mathrm{Mn}-3 \mathrm{Si}-3 \mathrm{Al}$ and $\mathrm{Fe}-23 \mathrm{Mn}-0.5 \mathrm{C}$ twinninginduced plasticity steels: Aspects of non-propagation of small fatigue cracks. Int J Fatigue 94:1-5

Koyama M, Zhang Z, Wang M, Ponge D, Raabe D, Tsuzaki K et al (2017c) Bone-like crack resistance in hierarchical metastable nanolaminate steels. Science 355:1055-1057

Koyama M, Sawaguchi T, Tsuzaki K (2018a) Overview of dynamic strain aging and associated phenomena in $\mathrm{Fe}-\mathrm{Mn}-\mathrm{C}$ austenitic steels. ISIJ Int 58:1383-1395

Koyama M, Yamamura Y, Sawaguchi T, Tsuzaki K, Noguchi H (2018b) Microstructural hardness heterogeneity triggers fatigue crack non-propagation in as-hot-rolled Fe-30Mn-3Si-3 Al twinninginduced plasticity steel. Int J Fatigue 108:18-24

Lankford J (1982) The growth of small fatigue cracks in 7075-T6 aluminum. Fatigue Fract Eng Mater Struct 5:233-248

Li H, Koyama M, Sawaguchi T, Tsuzaki K, Noguchi H (2015) Importance of crack-propagationinduced $\varepsilon$-martensite in strain-controlled low-cycle fatigue of high-Mn austenitic steel. Philos Mag Lett 95:303-311

Li B, Koyama M, Sakurada E, Yoshimura N, Ushioda K, Noguchi H (2016) Potential resistance to transgranular fatigue crack growth of $\mathrm{Fe}-\mathrm{C}$ alloy with a supersaturated carbon clarified through FIB micro-notching technique. Int J Fatigue 87:1-5

Li B, Koyama M, Hamada S, Noguchi H (2017a) Threshold stress intensity factor range of a mechanically-long and microstructually-short crack perpendicular to an interface with plastic mismatch. Eng Fract Mech 182:287-302 
Li B, Koyama M, Sakurada E, Yoshimura N, Ushioda K, Noguchi H (2017b) Underlying interstitial carbon concentration dependence of transgranular fatigue crack resistance in $\mathrm{Fe}-\mathrm{C}$ ferritic steels: The kinetic effect viewpoint. Int J Fatigue 98:101-110

Li B, Koyama M, Sakurada E, Yoshimura N, Ushioda K, Noguchi H (2018) Temperature dependence of transgranular fatigue crack resistance in interstitial-free steel and $\mathrm{Fe}-\mathrm{C}$ steels with supersaturated carbon: Effects of dynamic strain aging and dynamic precipitation. Int $\mathrm{J}$ Fatigue 110:1-9

Lin X, Koyama M, Gao S, Tsuji N, Tsuzaki K, Noguchi H (2019) Resistance to mechanically small fatigue crack growth in ultrafine grained interstitial-free steel fabricated by accumulative roll-bonding. Int J Fatigue 118:117-125

Maenosono A, Koyama M, Tanaka Y, Ri S, Wang Q, Noguchi H (2018) Crystallographic orientationdependent growth mode of microstructurally fatigue small crack in a laminated Ti-6Al-4V alloy. Procedia Struct Integr 13:694-699

Maenosono A, Koyama M, Tanaka Y, Ri S, Wang Q, Noguchi H (2019) Crystallographic selection rule for the propagation mode of microstructurally small fatigue crack in a laminated Ti-6Al-4V alloy: Roles of basal and pyramidal slips. Int J Fatigue 128:105200

Mayer HR, Stanzl-Tschegg SE, Sawaki Y, Hühner M, Hornbogen E (1995) Influence of transformation-induced crack closure on slow fatigue crack growth udner variable amplitude loding. Fatigue Fract Eng Mater Struct 18:935-948

Mei Z, Morris JW (1991) Analysis of transformation-induced crack closure. Eng Fract Mech 39:569-573

Mizumachi S, Koyama M, Fukushima Y, Tsuzaki K (2019) Growth behavior of a mechanically long fatigue crack in an FeCrNiMnCo high entropy alloy: A comparison with an austenitic stainless steel. Tetsu-to-Hagane 105:215-221

Murakami Y (2019) Metal fatigue: Effects of small defects and nonmetallic inclusions. Academic Press, Cambridge, USA

Murakami Y, Matsuoka S (2010) Effect of hydrogen on fatigue crack growth of metals. Eng Fract Mech 77:1926-1940

Niendorf T, Rubitschek F, Maier HJ, Canadinc D, Karaman I (2010) On the fatigue crack growthmicrostructure relationship in ultrafine-grained interstitial-free steel. J Mater Sci 45:4813-4821

Nikulin I, Sawaguchi T, Tsuzaki K (2013) Effect of alloying composition on low-cycle fatigue properties and microstructure of $\mathrm{Fe}-30 \mathrm{Mn}-(6-\mathrm{x}) \mathrm{Si}-\mathrm{xAl}$ TRIP/TWIP alloys. Mater Sci Eng: A 587:192-200

Nishikura Y, Koyama M, Yamamura Y, Ogawa T, Tsuzaki K, Noguchi H (2018) Non-propagating fatigue cracks in austenitic steels with a micro-notch: Effects of dynamic strain aging, martensitic transformation, and microstructural hardness heterogeneity. Int J Fatigue 113:359-366

Ogawa T, Koyama M, Tasan CC, Tsuzaki K, Noguchi H (2017) Effects of martensitic transformability and dynamic strain age hardenability on plasticity in metastable austenitic steels containing carbon. J Mater Sci 52:7868-7882

Ogawa T, Koyama M, Nishikura Y, Tsuzaki K, Noguchi H (2018) Fatigue behavior of Fe-Cr-Nibased metastable austenitic steels with an identical tensile strength and different solute carbon contents. ISIJ Int 58:1910-1919

Okamoto NL, Fujimoto S, Kambara Y, Kawamura M, Chen ZMT, Matsunoshita H et al (2016) Size effect, critical resolved shear stress, stacking fault energy, and solid solution strengthening in the CrMnFeCoNi high-entropy alloy. Sci Rep 6:35863

Omura T, Koyama M, Hamano Y, Tsuzaki K, Noguchi H (2017) Generalized evaluation method for determining transition crack length for microstructurally small to microstructurally large fatigue crack growth: Experimental definition, facilitation, and validation. Int J Fatigue 95:38-44

Onishi Y, Koyama M, Sasaki D, Noguchi H (2016) Characteristic fatigue crack growth behavior of low carbon steel under low-pressure hydrogen gas atmosphere in an ultra-low frequency. ISIJ Int $56: 855-860$

Ritchie RO, Lankford J (1986) Small fatigue cracks: A statement of the problem and potential solutions. Mater Sci Eng 84:11-16 
Sawaguchi T, Bujoreanu L-G, Kikuchi T, Ogawa K, Koyama M, Murakami M (2008) Mechanism of reversible transformation-induced plasticity of $\mathrm{Fe}-\mathrm{Mn}-\mathrm{Si}$ shape memory alloys. Scr Mater 59:826-829

Sawaguchi T, Nikulin I, Ogawa K, Sekido K, Takamori S, Maruyama T et al (2015) Designing $\mathrm{Fe}-\mathrm{Mn}-\mathrm{Si}$ alloys with improved low-cycle fatigue lives. Scr Mater 99:49-52

Shikama T, Takahashi Y, Zeng L, Yoshihara S, Aiura T, Higashida K et al (2012) Distinct fatigue crack propagation limit of new precipitation-hardened aluminium alloy. Scr Mater 67:49-52

Suresh S, Ritchie RO (1982) A geometric model for fatigue crack closure induced by fracture surface roughness. Metall Trans A 13:1627-1631

Suresh S, Ritchie RO (1984) Propagation of short fatigue cracks. Int Metals Rev 29:445-475

Suzuki K, Koyama M, Noguchi H (2018) Small fatigue crack growth in a high entropy alloy. Procedia Struct Integr 13:1065-1070

Takahashi Y, Shikama T, Nakamichi R, Kawata Y, Kasagi N, Nishioka H et al (2015) Effect of additional magnesium on mechanical and high-cycle fatigue properties of 6061-T6 alloy. Mater Sci Eng: A 641:263-273

Tanaka K, Nakai Y, Yamashita M (1981) Fatigue growth threshold of small cracks. Int J Fract 17:519-533

Tsuji N, Ito Y, Saito Y, Minamino Y (2002) Strength and ductility of ultrafine grained aluminum and iron produced by ARB and annealing. Scr Mater 47:893-899

Zeng L, Shikama T, Takahashi Y, Yoshihara S, Aiura T, Noguchi H (2012) Fatigue limit of new precipitation-hardened aluminium alloy with distinct fatigue crack propagation limit. Int J Fatigue 44:32-40

Zhang Z, Koyama M, Wang M, Tasan CC, Noguchi H (2019) Fatigue resistance of laminated and non-laminated TRIP-maraging steels: Crack roughness vs. tensile strength. Metall Mater Trans A 50:1142-1145

Open Access This chapter is licensed under the terms of the Creative Commons Attribution 4.0 International License (http://creativecommons.org/licenses/by/4.0/), which permits use, sharing, adaptation, distribution and reproduction in any medium or format, as long as you give appropriate credit to the original author(s) and the source, provide a link to the Creative Commons license and indicate if changes were made.

The images or other third party material in this chapter are included in the chapter's Creative Commons license, unless indicated otherwise in a credit line to the material. If material is not included in the chapter's Creative Commons license and your intended use is not permitted by statutory regulation or exceeds the permitted use, you will need to obtain permission directly from the copyright holder.

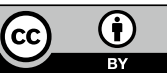

